\title{
Clinical assessment of a continuous intra- arterial blood gas monitoring system
}

Tokujiro Uchida MD, Koshi Makita MD, Yukio Tsunoda MD, Hidenori Toyooka MD, Keisuke Amaha MD.
We evaluated the clinical performance of a continuous intraarterial blood gas monitoring (CIABG) system which includes a fluorometric intravascular sensor. Seventeen patients undergoing elective surgery were monitored perioperatively with the CIABG system (PB3300; Puritan Bennett, Carlsbad, CA). Conventional laboratory blood gas analyses (BGA) were performed simultaneously whenever indicated, and the values were compared with those obtained from the CIABG system. Monitoring time ranged from 24 to $72 \mathrm{hr}$. The biases (average error between $\mathrm{PB} 3300$ and $\mathrm{BGA}$ ) of $\mathrm{pH}, \mathrm{PCO}_{2}$ and $\mathrm{PO}_{2}$ were $0.003 \mathrm{pH}$ unit, $-2.8 \mathrm{mmHg}$, and $0.9 \mathrm{mmHg}$ in the operating room (OR), and $0.005 \mathrm{pH}$ unit, $3.9 \mathrm{~mm} \mathrm{Hg}$, and $8.5 \mathrm{~mm} \mathrm{Hg}$ in the intensive care unit (ICU), respectively. The precision (standard deviation of the bias) of $\mathrm{pH}, \mathrm{PCO}_{2}$ and $\mathrm{PO}_{2}$ were $0.030 \mathrm{pH}$ unit, 2.1 $\mathrm{mmHg}$, and $29.9 \mathrm{mmHg}$ in the $\mathrm{OR}$ and $0.035 \mathrm{pH}$ unit, 3.8 $\mathrm{mmHg}$, and $14.7 \mathrm{mmHg}$ in the ICU, respectively. Although the PB3300 system was clinically useful as a trend monitor, the system's precision and reliability were unacceptable for estimation of true blood gas values.

Nous évaluons en clinique la performance d'un système de monitorage continu des gaz artériels (CIABG) qui contient un senseur fluorométrique intravasculaire. Dix-sept patients subissant une chirurgie programmée sont monitorisés pendant la période périopératoire avec le système CIABG (PB 3300; Puritan Bennett, Carlsbad, Californie). Des mesures conventionnelles de laboratoire (BGA) sont réalisées simultanément lorsqu' indiquées

\section{Key words}

ACID-BASE EQUILIBRIUM: measurement; EQUIPMENT: analyzer, oxygen, carbon dioxide, $\mathrm{pH}$; MEASUREMENT: acid-base, gas tensions.

From the Department of Anesthesiology and Critical Care Medicine, Tokyo Medical and Dental University, School of Medicine, Tokyo, Japan.

Address correspondence to: Dr. Tokujiro Uchida, Department of Anesthesiology and Critical Care Medicine, Tokyo Medical and Dental University, School of Medicine 1-5-45 Yushima, Bunkyo-ku, Tokyo 113, Japan.

Accepted for publication 12th September, 1993. et les résultats sont comparés avec ceux obtenus par le système $C I A B G$. La durée du monitorage se situe entre 24 et 72 heures. Le biais ('erreur moyenne entre $P B 3300$ et BGA) du pH, de la $\mathrm{PCO}_{2}$ et de la $\mathrm{PO}_{2}$ est de 0,003 unité de $\mathrm{pH},-2,8 \mathrm{~mm} \mathrm{Hg}$ et $0.9 \mathrm{mmHg}$ en salle d'opération (SO); de 0,005 unité de $p H$, $3,9 \mathrm{mmHg}$ et $8,5 \mathrm{mmHg}$ à l'unité de soins intensifs (USI). La précision (écart-type du biais de la moyenne) du $\mathrm{pH}$, de la. $\mathrm{PCO}_{2} 0,030$ unité de $\mathrm{PH}, 2,1 \mathrm{mmHg}$ et $29,9 \mathrm{~mm} \mathrm{Hg}$ en SO et de 0,035 par unité de $\mathrm{PH}, 3,8 \mathrm{mmHg}$ et $14,7 \mathrm{mmHg}$ à l'USI. Bien que le système $P H 3300$ soit cliniquement utile comme moniteur de tendance, sa précision et sa fiabilité sont inacceptables pour l'estimation des valeurs absolues des gaz sanguins.

The analysis of arterial blood gas values $\left(\mathrm{pH}, \mathrm{PaCO}_{2}\right.$, $\mathrm{PaO}_{2}$ ) is essential for the perioperative management of critically ill patients. Current analysis is periodic, because it is based on intermittent arterial sampling and in vitro measurements. Many clinicians have been looking forward to continuous monitoring, because it may improve patient care by allowing earlier detection of developing abnormalities in critical situations.

Placing a sensor into the patient, instead of drawing blood from the patient, is one of the approaches which enables continuous arterial blood gas monitoring. In the 1970's, miniaturized electrochemical $\mathrm{pH}, \mathrm{PCO}_{2}$, and $\mathrm{PO}_{2}$ electrodes were developed for intravascular placement, but they had some problems. First, they tended to show calibration drift. Second, because of technical limitations of miniaturization, it was difficult to make a single sensor package capable of measuring all three variables. '

Recently, optical fibre techniques and $\mathrm{pH}$ /oxygen sensitive dyes have been important in overcoming such hurdles. Since the mid-1970's, several types of fluorometric intra-arterial blood gas sensors have been developed and their accuracy has been verified both in vitro and in vivo. Among them, the CDI System 1000 (CDI-3M Healthcare, Irvine, CA), was the prototype three component blood gas sensor which contains optical fibres to measure $\mathrm{pH}, \mathrm{PCO}_{2}$, and $\mathrm{PO}_{2}$. It was $0.6 \mathrm{~mm}$ in diameter and easy to insert through a 20 -ga. cannula. Although in vitro 
TABLE I Patients' data

\begin{tabular}{rllll}
\hline No & Age $(y r)$ & Operation & Duration $(\mathrm{hr})$ & Reasons for sensor removal \\
\hline 1 & 30 & Renal artery reconstruction & 24 & Discharge from ICU \\
2 & 63 & OWRT & 72 & $72 \mathrm{hr}$ \\
3 & 71 & OWRT & 47 & Discharge from ICU \\
4 & 67 & OWRT & 50 & Inadequate AP monitoring $\dagger$ \\
5 & 56 & Right nephrectomy & 49 & Discharge from ICU \\
6 & 65 & OWRT & 47 & Discharge from ICU \\
7 & 62 & OWRT & 72 & $72 \mathrm{hr}^{*}$ \\
8 & 64 & OWRT & 72 & $72 \mathrm{hr}^{*}$ \\
9 & 71 & OWRT & 72 & $72 \mathrm{hr}$ \\
10 & 21 & OWRT & 50 & Discharge from ICU \\
11 & 44 & OWRT & 21 & Inadequate AP monitoring $\dagger$ \\
12 & 74 & OWRT & 24 & Inadequate AP monitoring $\dagger$ \\
13 & 54 & OWRT & 24 & Inadequate AP monitoring $\dagger$ \\
14 & 70 & Oesophageal bypass & 22 & Discharge from ICU \\
15 & 50 & OWRT & 23 & Inadequate AP monitoring $\dagger$ \\
16 & 67 & Aortofemoral bypass & 35 & Discharge from ICU \\
17 & 65 & OWRT & 72 & $72 \mathrm{hr}$ \\
\hline
\end{tabular}

OWRT: Oesophagectomy with right thoracotomy.

*Monitoring duration $>72 \mathrm{hr}$.

$\dagger$ Arterial pressure wave became over-damped and accurate arterial pressure monitoring was not possible.

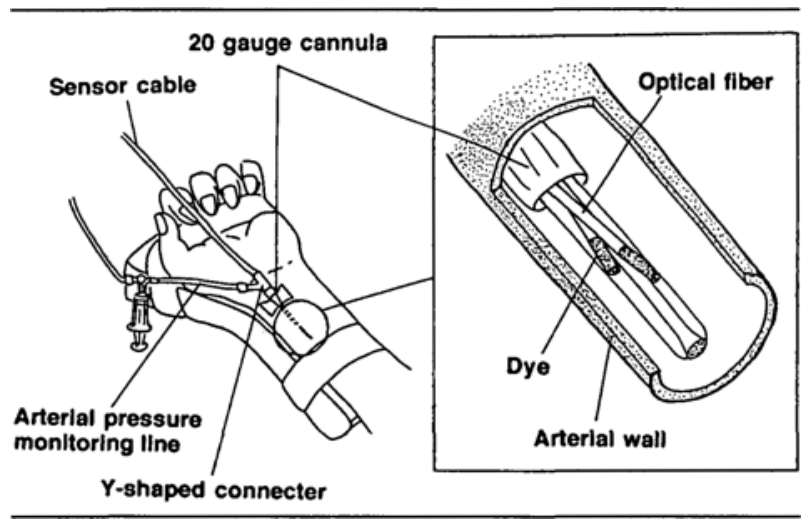

FIGURE 1 The intravascular sensor.

studies in tonometered bovine blood showed high accuracy, the data from patients gave relatively poor results. ${ }^{1-3}$ Recent reports have introduced new devices and verified their clinical accuracy. 4,5

The PB3300 (Puritan Bennett, Carlsbad, CA) is a new fluorometric continuous intra-arterial blood gas monitoring (CIABG) system. One of the new features is its sensor configuration. While the prototype sensors had the dyes fixed at the tip of the fibre, the PB3300 system have the dyes immobilized along the exterior circumference of the fibre ${ }^{6}$ (Figure 1). Such a configuration enables a larger total signal because of its much larger surface area. In vitro tests with tonometered whole blood or $\mathrm{pH}$ buffers have already shown its accuracy. In this report, we present the results of a clinical study of the performance of the CIABG system.

\section{Methods}

With institutional approval and individual informed consent, the study was performed in 17 patients undergoing elective surgery. Surgical procedures included oesophagectomy with right thoracotomy (13 of 17 patients) which required differential lung ventilation (DLV) (Table I).

After arrival of the patient in the operating room (OR), the radial artery was cannulated with a 20-gauge intravascular catheter (Becton Dickinson Insyte ${ }^{\circledR}$ ArtCath( arterial catheterization unit) under local anaesthesia. Through it, a sensor (PB-FOx Intra-Arterial Blood Gas Sensor, Puritan Bennett, Carlsbad, CA) was inserted into the artery. Arterial blood pressure was monitored by connecting the conventional pressure transducer to the side port of the catheter (Figure 1). Then $\mathrm{pH}, \mathrm{PaCO}_{2}$, and $\mathrm{PaO}_{2}$ were automatically measured every $20 \mathrm{sec}$. Blood samples were drawn from the arterial sampling port into dry heparinized syringes whenever the physician ordered blood gas analysis. In the operating room, arterial blood gas analyses were performed every 30-60 min. All samples were analyzed within a few minutes by a laboratory blood gas analyzer (BGA) (STAT Profile(I); NOVA biomedical, Waltham, MA). After the end of the surgical procedure, the sensor cable was disconnected from the monitor, and the patient was transferred to the intensive care unit (ICU) with the sensor in situ. In the ICU, the sensor cable was reconnected to the monitor, and monitoring was resumed. Continuous intra-arterial blood gas monitoring lasted for up to $72 \mathrm{hr}$. All values $\left(\mathrm{pH}, \mathrm{PaCO}_{2}\right.$, and $\mathrm{PaO}_{2}$ ) were printed out with the on-board printer. In ten of 17 patients, data were also recorded with a 
personal computer (Pc-9801 NT/S, NEC, Tokyo) connected to the PB3300 system through an RS-232C serial communication port.

\section{Sensor calibration}

\section{THE PB3300 SYSTEM}

Before insertion of the sensor into the arterial cannula, in vitro two-point calibration was carried out with two calibrating gas mixtures (the first gas contained $7 \% \mathrm{O}_{2}$, $2.8 \% \mathrm{CO}_{2}$ and the balance $\mathrm{N}_{2}$; the second gas contained $21 \% \mathrm{O}_{2}$ and $8.4 \% \mathrm{CO}_{2}$ and balance $\mathrm{N}_{2}$ ). The monitor was not recalibrated until the end of the monitoring.

\section{BGA SYSTEM (STAT PROFILE@)}

With the BGA system both one-point and two-point calibration were performed using the standard gas mixtures (the standard gas A contains $20.0 \% \mathrm{O}_{2}, 5.0 \% \mathrm{CO}_{2}$ and balance $\mathrm{N}_{2}$; the standard gas $\mathrm{B}$ contains $10.0 \% \mathrm{CO}_{2}$ and balance $\mathrm{N}_{2}$ ). A two-point calibration using both gas $A$ and $B$, was initiated automatically at intervals of several hours. A one-point calibration was performed using gas A at approximately $30 \mathrm{~min}$ intervals.

\section{Data analysis}

Data were divided into OR and ICU data groups.

\section{CORRELATION ANALYSIS}

Correlation analysis was performed between the corresponding data of PB3300 and BGA and correlation was described by Pearson's r value.

\section{ACCURACY AND REPEATABILITY}

Accuracy was quantified by the bias which is the averaged difference between PB3300 and BGA measurements. Repeatability was assessed by precision, which is the standard deviation (SD) of the bias. We also constructed Bland-Altman diagrams, ${ }^{7}$ by plotting the error on the ordinate and the mean of two methods on the abscissa, to represent the relationship between the measurement error and the true value.

\section{STABILITY ANALYSIS}

For stability analysis, the data were divided into six groups at $12 \mathrm{hr}$ sampling intervals. Intergroup differences were analyzed using ANOVA. If $F$ was $<0.05$, Scheffe $F$ test was performed as a post hoc evaluation.

\section{Results}

Twenty-one sensors were used in the study. During setup and calibration, three sensors were found to have "sensor fault" and were discarded. We failed to insert one sensor into the radial artery because of anatomical variation.
TABLE II Correlation analysis and accuracy

\begin{tabular}{lcc}
\hline & $O R$ & $I C U$ \\
\hline$p H$ & & \\
Pearson's r value & 0.77 & 0.79 \\
Bias (pH unit) & 0.003 & 0.005 \\
Precision (pH unit) & 0.030 & 0.035 \\
& & \\
PCO $_{2}$ & & \\
Pearson's r value & 0.77 & 0.8 \\
Bias (mmHg) & -2.8 & 3.9 \\
Precision (mmHg) & 2.1 & 3.8 \\
& & \\
PO & & \\
Pearson's r value & 0.95 & 0.98 \\
Bias (mmHg) & 0.9 & 8.5 \\
Precision (mmHg) & 29.9 & 14.7 \\
& & \\
PO ${ }_{2}<200 ~ m m H g$ & & \\
Bias (mmHg) & 0.6 & 7.0 \\
Precision (mmHg) & 18.1 & 12.0 \\
\hline
\end{tabular}

Monitoring time ranged from 24 to $72 \mathrm{hr}$ (mean 46 $\mathrm{hr}$ ). Five patients were monitored for $72 \mathrm{hr}$, and then according to the manufacturer's recommendation, the sensors were withdrawn. In five patients CIABG monitoring was interrupted because arterial pressure monitoring was interfered with by the sensor (arterial pressure wave was restored by the sensor removal). In the other cases CIABG monitoring was interrupted because patients left the ICU (Table I). No complications (e.g., vessel thrombus, haematoma formation, postoperative pain at insertion site, loss of pulse) were found in this study.

Arterial blood sampling and BGA were performed 196 times in the OR, and 151 times in the ICU. Scattergrams of the compared data from PB3300 and BGA are shown in Figure 2. Pearson's $\mathrm{r}$ values for $\mathrm{pH}, \mathrm{PCO}_{2}$, and $\mathrm{PO}_{2}$ are shown in Table II. There was no difference between the $r$ values obtained in the OR and those from the ICU.

The bias and precision of each variable are shown in Table II. Bland-Altman diagrams for $\mathbf{p H}, \mathrm{PCO}_{2}$, and $\mathrm{PO}_{2}$ are shown in Figures 3-6. In addition, the accuracy of $\mathrm{PO}_{2}$ values $<200 \mathrm{mmHg}$ was analyzed separately (Table II and Figure 6).

The results of the stability analysis are shown in Figure 7. Although the $\mathrm{PO}_{2}$ sensor was almost stable throughout the study, $\mathrm{pH}$ and $\mathrm{PCO}_{2}$ sensors showed considerable bias drift. Compared with the first $12 \mathrm{hr}$, the $\mathrm{pH}$ sensor tended to show higher values after $24 \mathrm{hr}$, and the $\mathrm{PCO}_{2}$ sensor tended to show higher values after $36 \mathrm{hr}$.

An example of plots of CIABG values, with superimposed laboratory measurements, is shown in Figure 8. In this patient, hypoxaemia occurred during DLV and resolved with $5 \mathrm{~cm} \mathrm{H}_{2} \mathrm{O} C P A P$ to the nonventilated nondependent lung. However, about three hours after the in- 


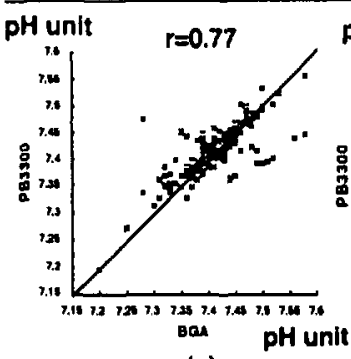

(a)

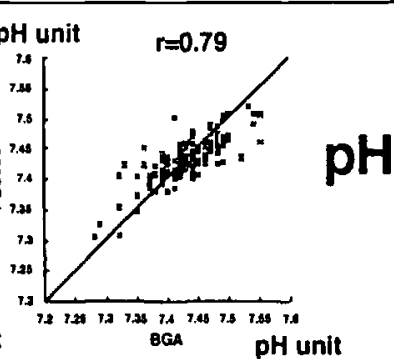

(b)

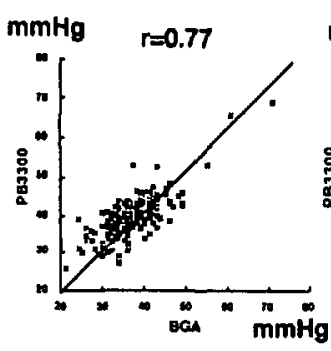

(c)

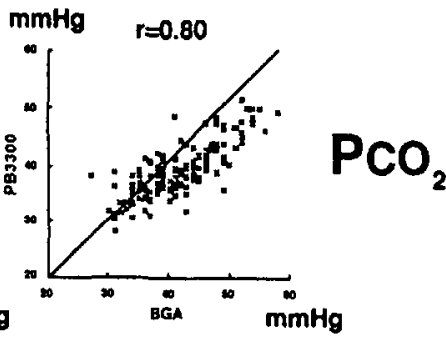

(d)

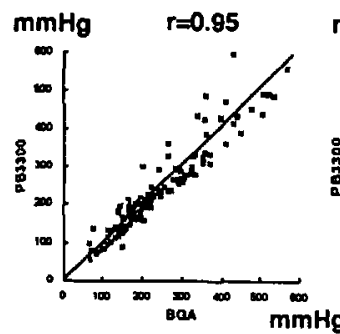

(e)

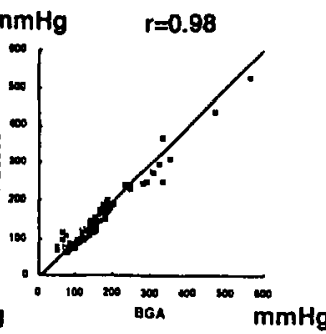

(i)

FIGURE 2 Scattergrams of correlation analysis. (a) $\mathrm{pH}$ data collected in $\mathrm{OR}$; (b) pH data collected in ICU; (c) $\mathrm{PCO}_{2}$ data collected in $\mathrm{OR}$; (d) $\mathrm{PCO}_{2}$ data collected in ICU; (e) $\mathrm{PO}_{2}$ data collected in $\mathrm{OR}$; (f) $\mathrm{PO}_{2}$ data collected in ICU. r: Pearson's r value.

sertion of the PB3300 sensor, hypoxaemia recurred and DLV was interrupted. In addition, $6.5 \mathrm{hr}$ after sensor insertion, the airway pressure increased rapidly and the endotracheal tube was found to be obstructed. The PB3300 sharply responded to fluctuation of blood gas data and was useful for early detection of each episode.

\section{Discussion}

Continuous intra-arterial blood gas monitoring is theoretically useful in the perioperative patient management for several reasons. ${ }^{1,2,4}$ With such monitoring, physicians can detect abnormal blood gas data more quickly than with intermittent conventional laboratory measurement. They can also observe trends and evaluate treatments. Frequent blood sampling is not necessary and the possibility of infection can be reduced. In addition, the fluorometric method, which is used in the PB3300 system, is free from electrical hazard and is not interfered with

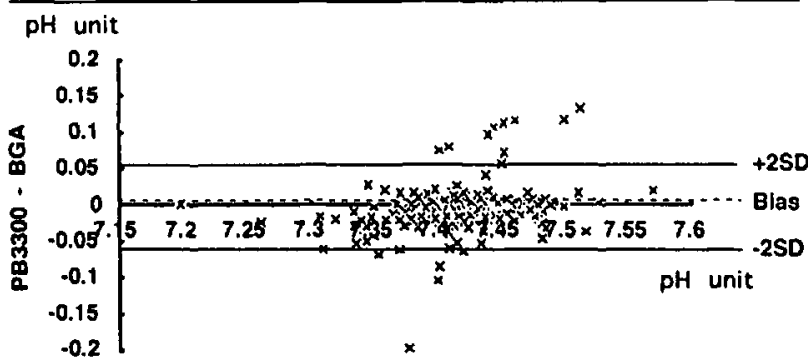

$1 / 2(P B 3300+B G A)$

(a)

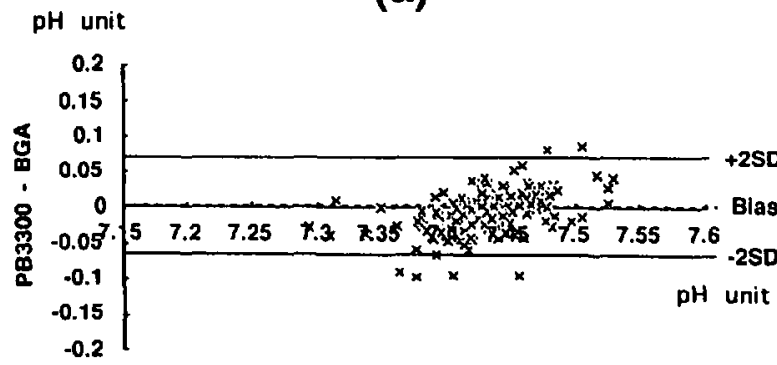

1/2 (PB3300 + BGA)

(b)

FIGURE 3 Bland-Altman diagrams of pH. Mean of PB3300 and laboratory blood gas analysis (BGA) are plotted on the $\mathrm{X}$-axis and the difference between the two methods (error) on the $Y$-axis. Data were collected in (a) OR, and (b) ICU.

by electrical noise. Because the sensor is placed directly in the radial artery, intra-arterial blood gas monitoring is hardly influenced by poor peripheral circulation which occasionally interferes with pulse oximetry. Compared with end-tidal $\mathrm{CO}_{2}$ for $\mathrm{PaCO}_{2}$ monitoring, continuous intra-arterial blood gas monitoring is not influenced by ventilation-perfusion inequality. Moreover, sensors in the bloodstream enable direct measurement of arterial blood and exclude modifications which may occur during sampling and carrying. For example, it is difficult to measure high $\mathrm{PO}_{2}$ values with current laboratory techniques, because oxygen in the sampled blood may be consumed by erythrocytes or diffused into the air during transport.

In this study, continuous intra-arterial blood gas monitoring with the PB3300 system was performed in 17 patients. The first purpose of the study was to investigate its in vivo accuracy in the perioperative period. The second purpose was to examine its clinical performance as a "continuous' monitor. To investigate the optode sensor accuracy, the values from the PB3300 were compared with the current laboratory electrode system. According to the instrument specifications of the Stat Profile system, its day-to-day precision is $<0.009$ for $\mathrm{pH},<2.3 \mathrm{mmHg}$ for $\mathrm{PCO}_{2}$, and $<3.4 \mathrm{mmHg}$ for $\mathrm{PO}_{2}$ with control so- 


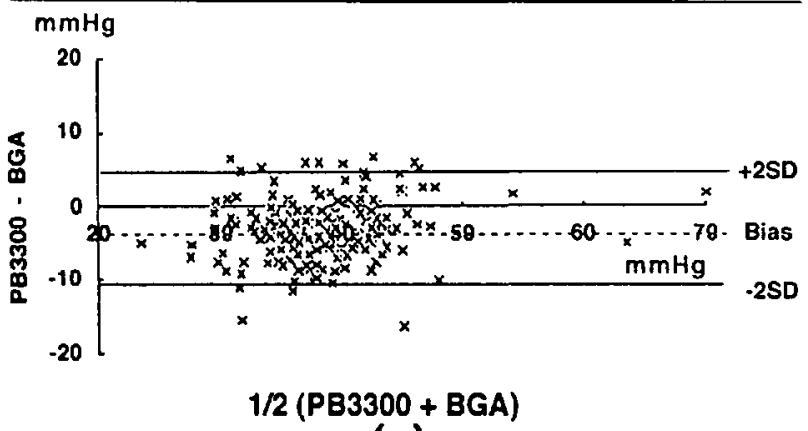

(a)

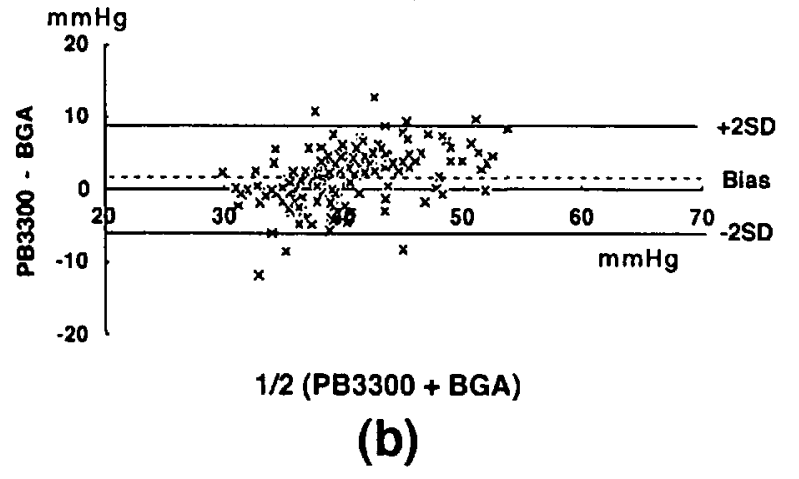

FIGURE 4 Bland-Altman diagrams of $\mathrm{PCO}_{2}$. Mean of $\mathrm{PB} 3300$ and $B G A$ are plotted on the $X$-axis and the difference between the two methods on the Y-axis. Data were collected in (a) OR, or (b) ICU.

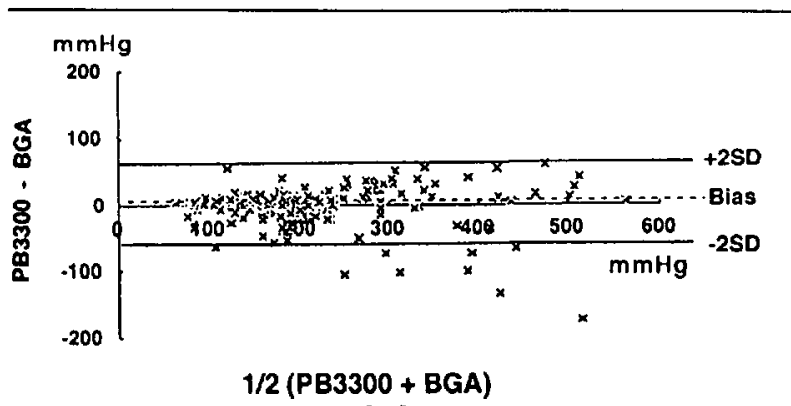

(a)

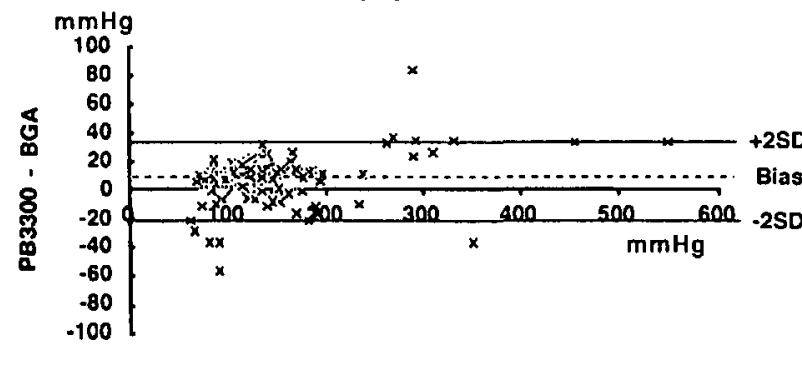

1/2 (PB3300+ BGA)

(b)

FIGURE 5 Bland-Altman diagrams of $\mathrm{PO}_{2}$. Mean of $\mathrm{PB} 3300$ and BGA are plotted on the $X$-axis and the difference between the two methods on the Y-axis. Data were collected in (a) OR, and (b) ICU.

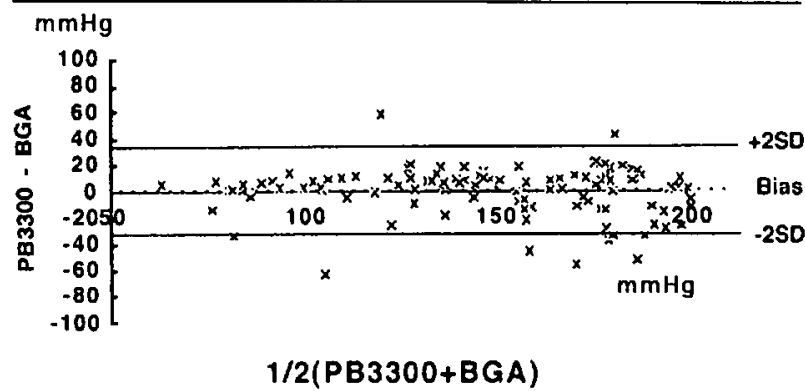

(a)

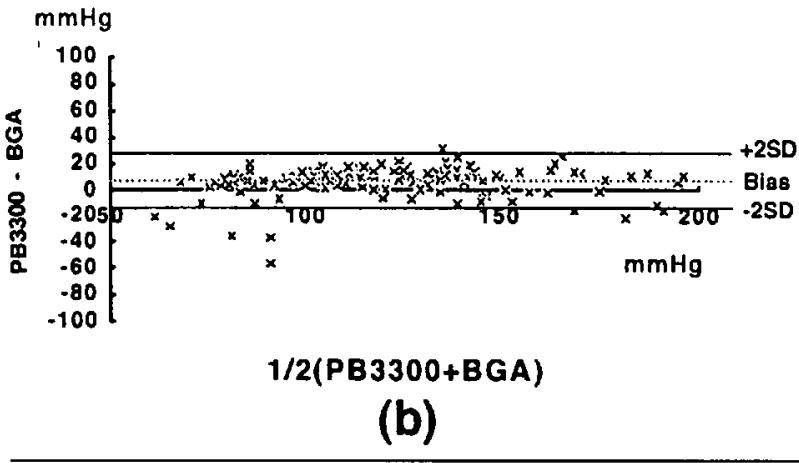

FIGURE 6 Bland-Altman diagrams of $\mathrm{PO}_{2}\left(\mathrm{PO}_{2}<200 \mathrm{mmHg}\right)$. Mean of PB3300 and BGA are plotted on the X-axis and the difference between the two methods on the Y-axis. Data were collected in (a) OR, and (b) ICU.

lutions. Thus the current electrode system can be regarded as an "established standard."

From this study, the PB3300 system fulfilled most requirements for trend monitoring. In particular during thoracotomy with differential lung ventilation, we consider that continuous intra-arterial blood gas monitoring is one of the most effective monitors. During differential lung ventilation, adequate oxygenation and appropriate ventilation are essential. Pulse oximetry and end-tidal $\mathrm{CO}_{2}$ monitoring are currently used for estimation of arterial blood gas values. But during the anaesthetic management of thoracotomy, the efficacy of these techniques may be limited. Circulatory changes, often caused by mediastinal compression or relative hypovolaemia, may modify pulse oximetry. Also, large ventilation-perfusion inequality may increase the discrepancy between arterial and end-tidal $\mathrm{CO}_{2}$ partial pressures. Monitoring with the PB3300 system enables information about arterial oxygenation and ventilation in real time. For example, Figure 8 clearly shows episodes such as hypoxaemia during differential lung ventilation, and hypercapnia caused by endotracheal tube obstruction.

As is obvious from Table II, the errors (difference of the values obtained by the two methods) of the $\mathrm{pH}$ and $\mathrm{PCO}_{2}$ sensor were less than $0.07 \mathrm{pH}$ unit and $7.8 \mathrm{mmHg}$ 

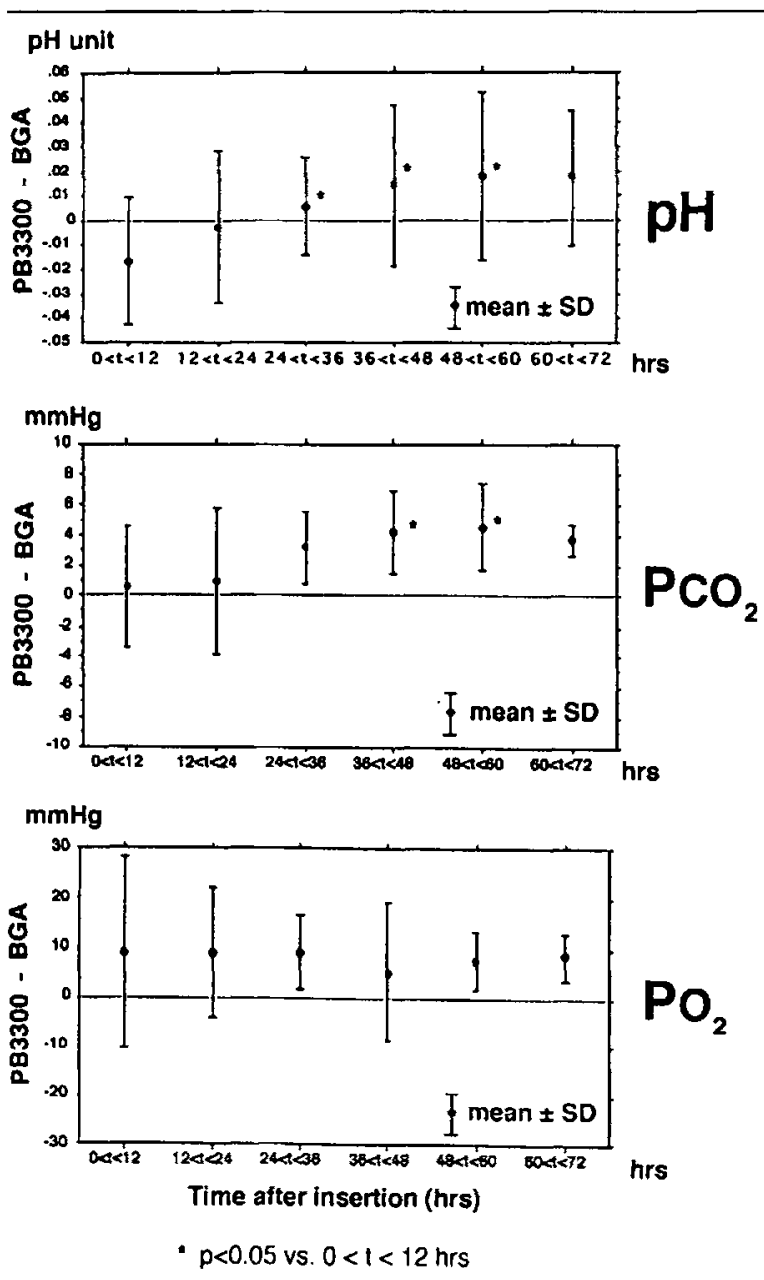

FIGURE 7 The results of stability analysis. The data were divided into six groups at $12 \mathrm{hr}$ sampling intervals. The differences between PB3300 and BGA in each period are shown with mean \pm SD.

respectively with $95 \%$ reliability. This may be acceptable for most clinical situations but such errors may still lead clinicians to erroneous evaluations in critically ill patients. On the contrary, the error of the $\mathrm{PO}_{2}$ sensor was $<60$ $\mathrm{mmHg}$ with $95 \%$ reliability. In the Bland-Altman diagram of $\mathrm{PO}_{2}$, plots exceeding $200 \mathrm{mmHg}$ are more scattered. For plots of $\mathrm{PO}_{2}<200 \mathrm{mmHg}$, the error was less than $36 \mathrm{mmHg}$ with $95 \%$ reliability. This is still inadequate for clinical application. For example, if the PB3300 system indicates the $\mathrm{PO}_{2}$ to be $70 \mathrm{mmHg}$, the true $\mathrm{PO}_{2}$ may be $34-106 \mathrm{mmHg}$. Interpretation of such a value is difficult.

These results were similar to reports of other intravascular optode systems. ${ }^{1,2,4}$ Several factors may influence the accuracy of the intravascular sensor. ${ }^{1-4}$ First, the intravascular site of the sensor limits its accuracy. Because it is placed in the artery, contact with the vessel wall

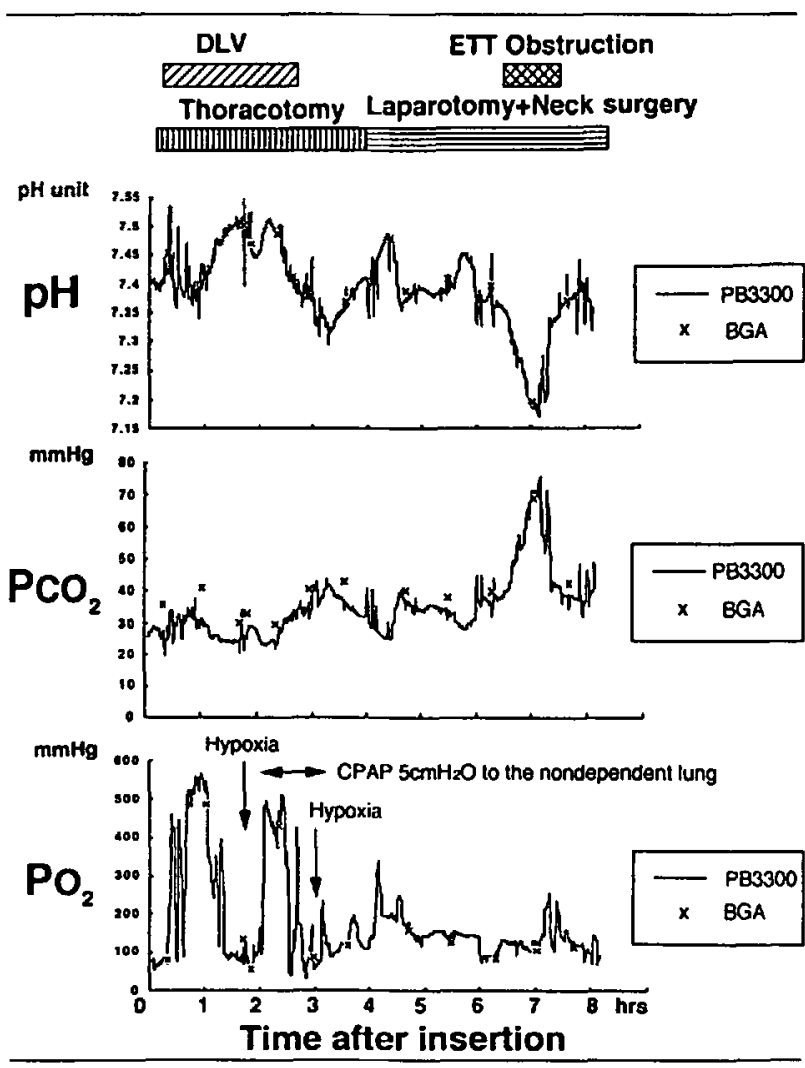

FIGURE 8 The intraoperative trend of Patient $\$ 9$. This patient had a radical resection of the thoracic oesophagus. During thoracotomy, differential lung ventilation was attempted, but was interrupted because of hypoxaemia. Although $5 \mathrm{~cm} \mathrm{H}_{2} \mathrm{O} \mathrm{CPAP}$ to the non-dependent lung relieved the first hypoxic event, recurrence of hypoxia could not be prevented. During neck surgery, the endotracheal tube (single lumen) was obstructed because of malposition. The PB3300 showed gradual rise of $\mathrm{PCO}_{2}$ and drop of $\mathrm{pH}$. After correcting the position, hypercapnia was rapidly restored. DLV: Differential lung ventilation; ETT: Endotracheal tube.

and/or clot formation may be inevitable. Mahutte et al. reported a "wall effect" of the CDI system 1000 intraarterial blood gas sensor. ${ }^{2}$ When the sensor tip touches the arterial wall, it measures intracellular $\mathrm{pH}, \mathrm{PCO}_{2}$ or $\mathrm{PO}_{2}$ of vascular wall cells. As a result, $\mathrm{pH}$ and $\mathrm{PO}_{2}$ decreased and $\mathrm{PCO}_{2}$ increased. Although the $\mathrm{PB} 3300$ sensor unit (PBFox) has each sensor at a different angle and location (Figure 1), the wall effect may not be overcome completely. Clots also consume oxygen and produce $\mathrm{CO}_{2}$. Although we have never observed clot formation on the sensor tip after its removal, micro clot formation during monitoring could not be excluded. Clots might be formed easily if the sensor tip touches the wall. In order to avoid these problems, wrist extension (stretching radial artery) and continuous flushing with heparinized saline is helpful but not sufficient. In particular for patients who have atherosclerotic and tortuous arteries, 
relocation of the sensor might be necessary. Another possibility of overcoming such problems is with the extraarterial fluorescent optode system. ${ }^{5}$ Although its clinical accuracy is better, it loses some features of continuous monitoring system.

Second, calibration methods have some problems. Because calibration gases of PB3300 system consist of $\mathrm{CO}_{2}$ $2.8 \%, \mathrm{O}_{2} 7.0 \%$ and $\mathrm{CO}_{2} 8.4 \%, \mathrm{O}_{2} 21 \%$, the reliable range for accuracy is limited. Especially for $\mathrm{PO}_{2}$, the more the actual value exceed these values, the less reliable is the measurement. Moreover, once the sensor is placed in the blood stream, its calibration cannot be adjusted except by making comparisons with a simultaneous blood sample. ${ }^{8}$ Two-point in vivo calibration is also difficult and, therefore, conventional quality control procedures, which are used in current laboratory analyzers and include frequent two-point calibrations, are not applicable to intravascular sensors.

According to the results of the study, calibration drift of the $\mathrm{pH}$ and $\mathrm{PCO}_{2}$ sensors occurs after $24 \mathrm{hr}$ (Figure 7). The causes of this phenomenon are unknown, but frequent in vivo calibration may be required to overcome this problem.

In conclusion, we used the PB3300 system in 17 patients and analyzed its clinical performance. From the viewpoint of trend monitoring, it gives much useful information in the perioperative period. However, because of its limited accuracy, estimating individual blood gas values with this system is unacceptable: occasional comparison with current blood gas analysis is preferable. Further refinement of the accuracy of such system is desirable before its substitution for current blood gas analyzers.

\section{References}

1 Barker SJ, Hyatt J. Continuous measurement of intraarterial $\mathrm{pHa}, \mathrm{PaCO}_{2}$, and $\mathrm{PaO}_{2}$ in the operating room. Anesth Analg 1991; 73: 43-8.

2 Shapiro BA, Cane RD, Chomka CM, Bandala LE, Peruzzi WT. Preliminary evaluation of an intra-arterial blood gas system in dogs and humans. Crit Care Med 1989; 17: 455-60.

3 Mahutte CK, Sassoon CSH, Muro JR, et al. Progress in the development of a fluorescent intravascular blood gas system in man. J Clin Monit 1990; 6: 147-57.

4 Zimmerman $J L$, Dellinger $R P$. Initial evaluation of a new intra-arterial blood gas system in humans. Crit Care Med 1993; 21: 495-500.

5 Shapiro BA, Mahutte CK, Cane RD, Gilmour IJ. Clinical performance of a blood gas monitor: a prospective, multicenter trial. Crit Care Med 1993; 21: 487-94.

6 Gotlieb A, Divers $S$, Hui HK. In vivo applications of fiberoptic chemical sensors. In: Wise L, Wingard L. (Eds.).
Biosensors with Fiberoptics. New Jersey: The Humana Press, 1991: 325-66.

7 Bland JM, Altman DG. Statistical methods for assessing agreement between two methods of clinical measurement. Lancet 1986; 1: 307-10.

8 Bashein G, Pino JA, Nessly $M L$, et al. Clinical assessment of a flow-through fluorometric blood gas monitor. J Clin Monit 1988; 4: 195-203. 